German Data Forum

(RatSWD)

\title{
RatSWD
}

Working Paper

No. 143

\section{Qualitative Interviewing of Respondents in Large Representative Surveys}

Olaf Groh-Samberg and Ingrid Tucci

May 2010 


\section{Working Paper Series of the German Data Forum (RatSWD)}

The RatSWD Working Papers series was launched at the end of 2007. Since 2009, the series has been publishing exclusively conceptual and historical works dealing with the organization of the German statistical infrastructure and research infrastructure in the social, behavioral, and economic sciences. Papers that have appeared in the series deal primarily with the organization of Germany's official statistical system, government agency research, and academic research infrastructure, as well as directly with the work of the RatSWD. Papers addressing the aforementioned topics in other countries as well as supranational aspects are particularly welcome.

RatSWD Working Papers are non-exclusive, which means that there is nothing to prevent you from publishing your work in another venue as well: all papers can and should also appear in professionally, institutionally, and locally specialized journals. The RatSWD Working Papers are not available in bookstores but can be ordered online through the RatSWD.

In order to make the series more accessible to readers not fluent in German, the English section of the RatSWD Working Papers website presents only those papers published in English, while the the German section lists the complete contents of all issues in the series in chronological order.

Starting in 2009, some of the empirical research papers that originally appeared in the RatSWD Working Papers series will be published in the series RatSWD Research Notes.

The views expressed in the RatSWD Working Papers are exclusively the opinions of their authors and not those of the RatSWD.

The RatSWD Working Paper Series is edited by:

Chair of the RatSWD (2007/2008 Heike Solga; since 2009 Gert G. Wagner) Managing Director of the RatSWD (Denis Huschka) 


\title{
Qualitative Interviewing of Respondents in Large Representative Surveys
}

\author{
Olaf Groh-Samberg $^{1,2}$ and Ingrid Tucci ${ }^{2,3}$ \\ ogrohsamberg[at]bigsss.uni-bremen.de / itucci[at]diw.de \\ ${ }^{1}$ BIGSSS, University of Bremen \\ ${ }^{2}$ DIW Berlin \\ ${ }^{3}$ Centre Maurice Halbwachs, ERIS, Paris
}

\begin{abstract}
Large representative surveys are using mixed methods to an ever-increasing degree. Biomarkers, register data, and experiments, for example, provide different types of data that can be linked with survey data. The use of qualitative interviewing of participants in longitudinal surveys is still rare, however, in the social sciences. Yet qualitative methods have proven just as valuable as quantitative methods in providing insights into social reality by reflecting the multidimensionality of individual life courses and lived realities. Furthermore, indepth interviews can provide a better understanding of individual decision-making processes and behavior resulting from more or less unconscious strategies. They also provide insights into decisive turning points in people's lives. Finally, by linking quantitative and qualitative data, the reliability of longitudinal information can be analyzed thoroughly in terms of accuracy as well as meaningfulness.
\end{abstract}

Keywords: mixed methods, qualitative data, longitudinal data, life course JEL Code: C81, C83, Z13 


\section{Introduction}

In the social and behavioral sciences, the use of mixed methods to address a particular research question typically involves a combination of quantitative and qualitative methodologies (see Brannen 2005; Bryman 2006; Tashakkori and Teddlie 2003). As an increasing range of data becomes available for scientific research - as documented throughout this volume and in the Discussion Paper Series of the German Data Council - the possibilities for mixed method approaches are growing. However, the use of mixed methods to link data from large representative surveys to qualitative data is still rare. A recent trend in longitudinal surveys worldwide consists in the linkage of survey data with data from different sources using diverse methodologies. For example, birth cohort studies or household panels like BHPS, HILDA, PSID, and SOEP, are collecting biomarkers, objective health measures, data from experiments, daily experience sampling or register and institutional context data to survey respondents (see the respective chapters in this volume and, e.g., the new British household panel Understanding Society). In this context of methodological innovations of longitudinal surveys, conducting in-depth qualitative interviews with sub-samples of respondents is one important and promising, yet only recently developing issue.

Up to now, qualitative methods have been used primarily with quantitative data to “embellish” analyses (Mason 2006a). However, mixed methods approaches in the sense of a triangulation of quantitative and qualitative data collected from the same respondents might help to understand the mechanisms underlying human behavior and individual life courses (see, e.g., Giele and Elder 1998). This is particularly true with respect to individual decisionmaking processes, coping strategies, and biographical “turning points," i.e., events or experiences that play a decisive role an individual's life course by correcting trajectories (see Abbot 1997). The importance of decision-making is not only central to the so-called rational actor model that has become a common reference model in the economic and social sciences and is typically associated with the large-scale quantitative data analysis (see Goldthorpe 2000); it is even considered a broader "unifying framework" for the behavioral sciences (Gintis 2007).

However, as quantitative research along these lines only observes the contexts, determinants, and outcomes of individual decisions - which are measured at least indirectly by means of proxy information - the decision-making process itself can only be modeled in a "reduced form" due to the lack of information on what is really going on in the individual's mind. This is exactly where qualitative in-depth interviews with sub-samples of survey respondents offer possibilities for new research prospects. Qualitative interviews may provide 
insights into how people select relevant information, what relevance they assign to them, and how their values, attitudes, perceptions, states of knowledge, and conscious as well as unconscious strategies are shaped by and shape their behavior.

Thus, qualitative methods can provide insights into something that still remains a "black box" for quantitative methods that aim to connect measured "inputs" with measured "outcomes" of human decisions and behavior and strive to establish a "causal link" by testing the theoretically derived hypotheses. From a qualitative perspective, this causal link appears to present itself as a dynamic and recursive system of "meanings." This does not mean, however, that the two methods are incompatible (see Brannen 2005; Kelle 2001). Rather, by developing explanations of human behavior - for example, regarding educational decisions the assumptions of quantitative research typically derived from the rational actor model, or any other theory, can be more directly tested, specified, and enriched or even rejected by means of qualitative methods that allow a deeper understanding of how choices come about.

\section{The State of the Art}

Although still rather rare, the linkage of survey data with qualitative interviews seems to have reached scientific maturity, and is being discussed increasingly within the scientific community (see Tashakkori and Teddlie 2003). Although there are still forces at work promoting the separation of quantitative and qualitative methods - separate training courses, academic journals, funding schemes, and university chairs - efforts are also underway seeking to actively press forward with mixed method research (see, e.g., Bryman 2006; Mason 2006b).

It has become apparent that mixed methods are not a third way, or even a third methodology in their own right, and that there exists a broad variety of means by which mixed method approaches can be rationalized and employed in empirical research. A metaanalysis by Bryman (2006) of more than 200 research projects employing mixed methods reveals that mixed methods are mainly employed in sociology, and that they combine selfadministered questionnaire surveys with semi-structured interviews to address specific research questions. Mixed methods are typically used to produce "complementary" data or to "enhance" data, facilitating the examination of different perspectives or different aspects of a particular research question. However, there is no strict methodology that determines how different methods should be linked. Rather, there are good arguments for designing and 
linking mixed methods based on theoretical principles in order to produce non-redundant and non-trivial results (see Kelle 2001).

Mixed methods approaches used to be used primarily in larger-scale research projects aiming to explore new, uncharted research fields. The seminal work of Marie Jahoda, Paul Lazarsfeld et al. (1933) "Marienthal: The Sociography of an Unemployed Community” dealt with the challenges posed by the external economic shock of mass unemployment during the 1930s. The sociology and psychology of the time was entirely incapable of predicting how modern society might respond to such a shock, so the research team attempted to collect as wide a variety of data as possible, ranging from the observation of walking speed, conventional household interviews to content analysis of school essays. Once testable concepts had been produced - such as the concept of individual stages of unemployment experiences - they could then easily be tested using standard quantitative methods or more focused qualitative interviews from predefined samples. This gave rise to Lazarsfeld's idea that qualitative methods could be used to develop hypotheses and that quantitative methods could be used to test hypotheses. Following this idea, mixed methods research designs often use qualitative interviews and ethnographic research to develop a hypothesis, and survey questionnaires to test the hypothesis. However, the strict two-stage model of sequentially combining qualitative and quantitative methods has not become widespread (see Leech and Onwuegbuzie 2009; Creswell et al. 2003). Rather, many larger mixed methods research projects use qualitative methods to supplement quantitative surveys in order to gain a fuller understanding of the "real lives" of the individuals and households surveyed (see, e.g., Portes and Fernández-Kelly 2008; Mayer and Schulze 2009a, 2009b).

\section{The unique potential of qualitative projects based on longitudinal survey respondents}

In some sense, longitudinal surveys such as household panel or birth cohort studies can be said to follow in the tradition of Jahoda et al. (1933) in establishing a large survey to analyze how households adapt to social and economic changes and in turn contribute to social change. Longitudinal surveys provide a constantly expanding body of diverse data and are therefore becoming multiple or mixed method enterprises to an increasing degree. Conducting qualitative interviews with long-term survey respondents provides a unique opportunity for a real triangulation of different types of data on people's life courses. In long-running longitudinal studies, it is possible to conduct biographical interviews with long-term respondents for whom more than a decade of prospectively collected panel data are available. 
In principle, the longitudinal data can also be linked with register data from employment or social insurance agencies.

Triangulations like these would make it possible to thoroughly analyze the validity, reliability, and meaningfulness of panel data. Biographical crises or "turning points" in the life course as reported in qualitative interviews can be checked against the standardized yearly measures collected in longitudinal surveys (e.g., life satisfaction). Is it possible to detect biographical crisis through quantitative longitudinal data? Are respondents able to remember negative events like unemployment or the timing of a divorce? Does the use of combined methodologies affect non-response behavior (item non-response as well as partial unit nonresponse or panel attrition)?

Mixed method research designs are often used for validation purposes: this is the case with qualitative interviews or experiments being used to validate and/or improve measures in survey questionnaires (see, e.g., Dohmen et al. 2010 for measuring risk aversion). Cognitive interviewing has been developed as a qualitative tool for this purpose (see Willis 2005). Moreover, by drawing on a large ongoing survey, one can systematically select respondents who appeared to be particularly interesting in the quantitative analysis for qualitative interviews. A common feature of such designs is the construction of typologies by clustering survey data and then selecting "representative” respondents for each cluster, or by selecting extreme cases or even outliers for more in-depth analysis (see Portes and Fernández-Kelly 2008 for an outlier analysis).

Apart from investigating the methodological effects arising from the type of data, qualitative interviewing of respondents to longitudinal surveys allows insights in a wide range of particular research questions, such as school choice, educational and occupational aspirations, and family formation. Qualitative interviews can be carried out with entire households and address issues such as family relations within and across households, social networks, perceptions of neighborhoods, schools, employers, and how these shape life goals and individual behavior. However, these rich opportunities have only recently entered the research agenda of longitudinal surveys. 


\section{Review of qualitative projects based on longitudinal survey respondents}

To date, very few projects have been carried out involving qualitative interviews with respondents to longitudinal surveys, but a growing number of such projects have started recently or are currently under planning:

- For the German context, about three dozen interviews were conducted with respondents from the 1971 birth cohort of the German Life History Study. Using narrative interviews, Mayer and Schulze (2009a) used a "modest mixed-methods strategy" to analyze the life courses of this generation in West and East Germany and, in another study, to study parenthood processes in order to provide evidence of mechanisms resulting in delayed family formation (Mayer and Schulze 2009b: 12).

- In a project at the University of Manchester on interactions between and within generations, data from the English Longitudinal Study of Ageing were linked to qualitative interviews of between 25 and 30 respondents and approximately 20 of their descendants. ${ }^{1}$ The goal of the study was to understand intergenerational transfers and communication and the role played by older people.

- In a project conducted at the Center for Longitudinal Studies at the University of Manchester, qualitative interviews are planned with about 180 respondents (aged 50) from the 1958 British Birth Cohort Study in order to understand the driving forces and the dynamics underlying voluntary social engagement.

- In the UK, qualitative interviews are planned for the new British household panel “Understanding Society” (Usoc)2.

- In the US, Portes and Fernández-Kelly (2008) also used mixed methodologies to analyze data from the Children of Immigrants Longitudinal Study (CILS). They conducted narrative interviews with 50 second-generation youths and their families to understand how young respondents have coped with disadvantages during their childhood and teen years and to examine their educational success.

- Also in the US, researchers linked data from the Women's Employment Study (WES) with qualitative data gathered from a sub-sample of the survey's respondents (approximately

More details on this project are available at http:/www.socialsciences.manchester.ac.uk/realities/research/generations/

For more details, see http://www.understandingsociety.org.uk/design/features/qualitative.aspx as well as http://www.understandingsociety.org.uk/news/latest/ and http://www.esrc.ac.uk/ESRCInfoCentre/research/resources/UKHLS.aspx

6 
70) in order to analyze processes of union formation among low-income women and to formulate hypotheses that can be tested by the use of panel data (see Seefeldt 2008). ${ }^{3}$

- Researchers have used mixed methodologies on data from the South African KIDS Survey (KwaZulu-Natal Income Dynamics Study) in order to understand the factors explaining transitions into or out of poverty (see Adato, Lund and Mhlongo 2006). Qualitative data was collected on members of eight households selected from this first large-scale longitudinal study of household poverty in South Africa.

\section{Challenges}

Linking qualitative in-depth interviews to quantitative surveys poses new challenges. First of all, ethical and data protection issues have to be considered and resolved (see Leahey 2007). For legal reasons, survey respondents have to declare their willingness to participate in the survey, and this declaration should explicitly include their agreement to participate in personal in-depth interviews. Moreover, respondents need to understand exactly how qualitative interviews - or the transcript, audio, or video file - will be linked with the quantitative microdata.

For longitudinal survey respondents, time-consuming in-depth interviews may negatively affect survey participation, and requests to divulge intimate biographical details could impair the respondent's relationship to the interviewer. From what we know so far about the effects of introducing new and more demanding kinds of surveying in ongoing longitudinal studies, they seem to strengthen rather than weaken respondents' personal commitment to the survey.

An important challenge in developing the social science research infrastructure in the future relates to the rules of access to qualitative data on survey respondents. Those responsible for managing longitudinal surveys need to establish working models that can provide external researchers the opportunity to interview respondents. 


\section{Recommendations}

The inclusion of qualitative in-depth interviewing in the repertoire of data collection methods used in sample surveys is a highly promising innovation in terms of both methodological and substantial research. However, there is still a long way to go in laying the foundations and exploring the possibilities and limits of such an approach.

- Theory \& methodology: More extensive use of qualitative methods in surveys should be based on theoretical and methodological proposals that guide the triangulation of qualitative and quantitative methods.

- Ethics, data protection, and access: Ethical and data protection issues need to be addressed. Rules for access to samples of respondents should be established.

- Exploration: The possibilities and problems of conducting semi-structured and biographical interviews should be explored with rather small test samples of long-term survey respondents, focusing on methodological issues of “triangulating” life courses. 


\section{References:}

Abbott, Andrew (1997): On the Concept of Turning Point. Comparative Social Research 16: 89-109.

Adato, Michele; Lund, Francie and Mhlongo, Phakama (2007): Methodological Innovations in Research on the Dynamics of Poverty: A Longitudinal Study in KwaZulu-Natal, South Africa. World Development 35(2): 247-263.

Brannen, Julia (2005): Mixing methods: the entry of qualitative and quantitative approaches into the research process. International Journal of Social Research Methodology 8(3): 173-84.

Bryman, Alan (2006): Integrating quantitative and qualitative research: how is it done? Qualitative Research 6(1): 97-113.

Creswell, John W., Plano-Clark, Vicki L., Gutmann, Michelle L., and Hanson, Wiliam E. (2003): Advanced mixed methods research designs. In Tashakkori and Teddlie (Eds.): Handbook of mixed methods in social and behavioral research. Thousand Oaks: Sage, pp. 209-240.

Dohmen, Thomas; Falk, Armin; Huffman, David; Sunde, Uwe; Schupp, Jürgen and Wagner, Gert G. (2010): Individual Risk Attitudes: New Evidence from a Large, Representative Experimentally-Validated Survey. Journal of the European Economic Association 7 (forthcoming)

Giele, Janet Z. and Glen H. Elder (Eds.) (1998): Methods of Life Course Research: Quantitative and Qualitative Approaches. Thousand Oakes, London, New Delhi: Sage.

Gintis, Herbert (2007): A framework for the unification of the behavioral sciences. Behavioral and Brain Sciences 30: 1-61.

Goldthorpe, John H. (2000): The Quantitative Analysis of Large-scale Data Sets and Rational Action Theory: For a Sociological Alliance. In: John H. Goldthorpe: On Sociology: Numbers, Narratives, and the Integration of Research and Theory. Oxford University Press, pp. 94-114.

Jahoda, Marie; Lazarsfeld, Paul L. and Zeisel, Hans (1933): Marienthal: The Sociography of an Unemployed Community - Translated by the authors with John Reginait and Thomas Elsaesser. Chicago 1971: AldineAtherton.

Kelle, Udo (2001): Sociological Explanations Between Micro and Macro and the Integration of Qualitative and Quantitative Methods. Forum: Qualitative Social Research 2(1).

Laurie, Heather and Sullivan, Oriel (1991): Combining qualitative and quantitative methods in the longitudinal study of household allocations. Sociological Review 39: 113-139.

Leahey, Erin (2007): Convergence and confidentiality? Limits to the implementation of mixed methodology. Social Science Research 36: 149-158.

Mason, Jennifer (2006a): Six strategies for mixing methods and linking data in social science research. Real Life Methods Working Paper.

Mason, Jennifer (2006b): Mixing methods in a qualitatively driven way. Qualitative Research 6(1): 9-25.

Mayer, Karl Ulrich and Schulze, Eva (2009a): Die Wendegeneration. Campus. Frankfurt am Main/ New York.

Mayer, Karl Ulrich and Eva Schulze (2009b): Delaying Parenthood in East and West Germany. A Mixed-Methods Study of the Onset of Childbirth and the Vocabulary of Motives of Women of the Birth Cohort of 1971. In: Andersson, G., L. Bernardi, H. Kulu, and G. Neyer (Eds.). The Demography of Europe: Trends and Perspectives. Berlin: Springer.

Leech, Nancy L. and Onwuegbuzie, Anthony J. (2009): A typology of mixed methods research designs. Quality and Quantity 43(2): 265-75

Portes, Alejandro and Fernández-Kelly, Patricia (2008): No Margin for Error: Educational and Occupational Achievement among Disadvantaged Children of Immigrants. The Annals of the American Academy of Political and Social Science 620(1): 12-36.

Seefeldt, Kristin S. (2008): Working after welfare: how women balance jobs and family in the wake of welfare reform. W.E. Upjohn Institute for Employment Research, Michigan.

Tashakkori Abbas, Teddlie Charles (Eds.) (2003): Handbook of Mixed Methods in Social and Behavioural Research. Thousand Oaks: Sage.

Willis, Gordon B. (2005): Cognitive Interviewing: A Tool for Improving Questionnaire Design. Thousand Oaks: Sage. 